\title{
SDS-PAGE Profile Analysis of SeM-like Protein of Streptococcus equi subspecies equi
}

\author{
Shaimaa Mahmoud Elsayed Abdelmageed ${ }^{1 *}$, Soumaya Elsayed Ahmed El-Shafii ${ }^{2}$ and Jakeen Kamal Abdel Haleem El Jakee ${ }^{3}$ \\ ${ }^{I}$ Pyrogen Unit, Animal Health Research Institute, Dokki, Giza, Egypt. \\ ${ }^{2}$ Bacteriology Department, Animal Health Research Institute Dokki, Giza, Egypt. \\ ${ }^{3}$ Microbiology Department, Faculty of Veterinary Medicine, Cairo University, P.O. 12211, Giza, Egypt. \\ *Corresponding author`s Email: shema.mahmoud59@gmail.com; (D) ORCiD: 0000-0002-1738-0279
}

\begin{abstract}
S. equi subspecies equi, causing strangles in equine, is characterized by comprising a major virulence factor called M like protein or SeM protein. This study aimed to extract SeM protein from local S. equi strain in Egypt and to detect its antigenic components. After centrifugation, the native 58 kilo Dalton (kDa) SeM protein was detected both in the supernatant and sediment of the prepared extract. With modification by more centrifugation, the formed supernatants were separated and fractionated using SDS-PAGE with silver nitrate staining, which led to the appearance of a band at Molecular Weight (MW) $70.9 \mathrm{kDa}$. in SeM1, the presence of 7 bands at MW of 105, 87.8, $70.9,61.1,44,37.9$ and 18.4 in SeM2; 5 bands at MW 70.9, 58.9, 37.2, 29.8 and 18.3kDa in SeM3 and 4 bands at MW of 72.0, 58.6, 29.8 and $18.0 \mathrm{kDa}$ in SeM4. This study suggested that a further modification of SeM extraction revealed the presence of heterogeneous complex fragments of SeM.
\end{abstract}

Key words: SeM protein, SDS-PAGE, Strangles, Streptococcus equi subspecies equi

\section{INTRODUCTION}

Streptococcus equi subspecies equi is the causative agent of an important, frequently diagnosed infectious disease in equine, which is known as strangles (Kasuya et al., 2019). Although Jordanus Ruffus reported strangles disease in 1251 for the first time, it is still considered as one of the most frequently detected diseases in horses in the world (Ikhuoso et al., 2019). Strangles disease is featured by the abscesses of the head and neck lymph nodes (Robinson et al., 2018). Detection and differentiation of $S$. equi subtypes could typically be accomplished using traditional culture, Polymerase Chain Reaction (PCR), matrix assisted laser desorption/ ionization-time of flight mass spectrometry (MALDI-TOF MS), and SeM sequencing (Tartor et al., 2019). S. equi virulence and immunogenicity were referred to several components, including M-protein (Taylor and Wilson, 2006). $58 \mathrm{kDa}$ SeM protein was detected and identified as one of the main virulence factors of Streptococcus equi subspecies equi and also considered as one of its protective antigens. Opsonogenic action of $\mathrm{SeM}$ is restricted to S. equi, but not to S. zooepidemicus, while the opsonogenic action of SzPSe is restricted for $S$. zooepidemicus, but not to $S$. equi (Timoney et al., 1997). M-proteins or M-like proteins were considered as cell surface proteins that bind fibrinogen and possess antiphagocytic activity (Staali et al., 2003). Resistance to phagocytosis and killing required the presence of both capsule and SeM, with the antiphagocytic property of SeM being significantly decreased in the absence of capsule (Timoney et al., 2014).

Sodium Dodecyl Sulphate Poly-Acrylamide Gel Electrophoresis (SDS-PAGE), the first step of immunoblotting, involved the electrophoretic separation of proteins on the gel (Kalagiri et al., 2020). Protein complex mixtures can be separated using electrophoresis, which can be also used for protein purification for other applications. Polyacrylamide gel electrophoresis involves an electrical field that induced the migration of protein through pores in a polyacrylamide gel matrix.

The protein migration rate was determined by pore size and protein charge, size, and shape. Continuous SDS-PAGE is considered as a non-complicated method, in which the same buffer could be used for both the gel and electrode solutions (Gallagher, 2006). SDS-PAGE is a reliable method for peptide mapping for the peptide fragments separation. The comparison of the separation patterns reveals the proteins structural relationship. The peptides moderate separation could be completed by this technique, which is uncomplicated, cheap and without any special equipment (Judd, 2009). The present study aimed to produce SeM-like protein and to analyze its components using SDS-PAGE.

\section{MATERIALS AND METHODS}

\section{The isolation}

A locally isolated S. equi subspecies equi was obtained from Equine Bacterial Disease Lab (Animal Health Research Institute, Egypt). It was cultured on blood agar and incubated for 24 hours at $37^{\circ} \mathrm{C}$ with $10 \% \mathrm{Co}_{2}$ (Boyle et al., 2018). The isolate, which showed $\beta$-hemolysis was subjected to Lancefield grouping using the Mastastrep Kit (Biomerieux) as identified as Group C and biochemical identification using API20 Strep (Biomerieux) (Ferris et al., 2017). 


\section{Acid Extraction of SeM-like protein of Streptococcus equi subspecies equi}

According to Woolcock (1974) with some modification, S. equi local strain was grown on Todd-Hewitt broth (Oxoid), supplemented with glucose and incubated for 24 hours at $37^{\circ} \mathrm{C}$. The culture was centrifuged at 3000 round per Minute (rpm) $/ 5$ minutes for cells collection, washed twice with normal saline, followed by a wash with Distilled Water (DW) and two further washings in phosphate buffer saline (PBS), pH 7.0. Finally, the cells were suspended in saline; the $\mathrm{pH}$ was adjusted to 2.4 with 1 Normality $(\mathrm{N}) \mathrm{HCl}$, and heated to $95^{\circ} \mathrm{C}$. in a boiling water bath for 12 minutes. The suspension was cooled and neutralized with $1 \mathrm{~N} \mathrm{NaOH}$ and centrifuged at $3000 \mathrm{rpm} / 5$ minutes. The bacterial sediment was re-suspended in saline, and the extraction procedure was repeated. The combined supernatants were next treated with $6 \mathrm{~N} \mathrm{HCl}$ to give a flocculent precipitate at $\mathrm{pH}$ 2.0. This acidified material was kept refrigerated for 2 hours and centrifuged at $3000 \mathrm{rpm} / 10$ minutes. The deposit was re-dissolved in 0.1M PBS, pH 8.0. The ribonuclease enzyme was added at a final concentration of $0.001 \mathrm{mg} / \mathrm{ml}$. Two chloroform drops were added, and the solution was dialyzed against 30 volumes of $0.01 \mathrm{M}$ PBS, pH 8.0. Ribonuclease digestion continued for 5 hours at $37^{\circ} \mathrm{C}$., followed by overnight dialysis at $4^{\circ} \mathrm{C}$. The ammonium sulfate fractionation of the dialyzed fluid was performed at $4^{\circ} \mathrm{C}$. The solution was saturated to $30 \%$ and centrifuged at $3000 \mathrm{rpm} / 10$ minutes. The resulting supernatant was then saturated to $60 \%$, and the solution was mechanically stirred at $4^{\circ} \mathrm{C}$ for 30 minutes. The obtained pellet after centrifugation was solubilized in $10 \mathrm{ml}$ of DW and dialyzed against PBS for 18 hours at $4^{\circ} \mathrm{C}$. The modification was applied by further centrifugation $(3000 \mathrm{rpm}$ $/ 10$ minutes) for both the supernatant and sediment of the SeM acid extract, and the resulting supernatants of both centrifugation were also analyzed, with four samples being analyzed electrophoretically, including SeM acid extract sediment (SeM1), SeM acid extract supernatant (SeM2), supernatant from centrifuged SeM1 (SeM3), and supernatant from centrifuged SeM 2 (SeM 4).

\section{Detection of SeM protein concentration}

The required reagents consisted of solution $\mathrm{A}$, which contained $2 \%$ sodium carbonate in $0.10 \mathrm{~N} \mathrm{NaOH}$, solution B, which contained $1 \%$ sodium tartrate, solution C, $0.5 \%$ copper sulfate, solution D, which was freshly prepared from 48 ml of solution A, $1 \mathrm{ml}$ solution B, and $1 \mathrm{ml}$ solution C Folin- ciocalteau reagent (Fischer scientific, Co., USA). Bovine Serum Albumin (BSA, Sigma- Aldrich Co., USA) was used to prepare a standard protein curve in the range of 0.625 to $10 \mathrm{mg} / \mathrm{ml}$. According to Lowry et al. (1951), ten $\mu$ l of the samples were diluted to a final volume of $0.2 \mathrm{ml}$ in DW. The different dilutions of BSA were mixed in the same amounts of the samples as standard. $0.2 \mathrm{ml}$ of DW was used as a blank. $1 \mathrm{ml}$ of solution $\mathrm{D}$ was added to all test tubes, mixed well and left at room temperature for $10 \mathrm{minutes} .0 .1 \mathrm{ml}$ of diluted folin reagent (V/V with DW) was added to each tube followed by rapid vortex, and incubated in a dark place for 30 minutes at room temperature. The standard and the samples were read against the blank at $750 \mathrm{~nm}$ wavelength using a spectrophotometer. The standard curve was blotted using the diluted standard protein solutions. The unknown protein concentration was calculated from the curve slope.

\section{Electrophoresis analysis}

Four samples of prepared SeM-like protein were analyzed electrophoretically by using SDS-PAGE including SeM acid extract sediment (SeM1), SeM acid extract supernatant (SeM2), supernatant of centrifuged SeM1 (SeM3), and supernatant of centrifuged SeM 2 (SeM 4) according to the method of Laemmli (1970).

After the gel sandwich was assembled, the separating gel was carefully poured to minimize trapped air bubbles. One $\mathrm{cm}$ layer of M-butanol was added to keep the gel surface flat. The gel was allowed to polymerize, before pouring the stacking gel where the comb was inserted obliquely. Following the gel polymerization, it was placed in electrophoresis chamber filled with running buffer and the comb was carefully removed to avoid damaging well ears and trapped air bubbles. The four samples $(70 \mu \mathrm{g} /$ well each), were diluted at 1:4 ratio using the sample buffer and immersed in a boiling water bath for 4 minutes to ensure denaturation of the protein. The pre-stained protein ladder; wide range 10$250 \mathrm{kDa}$, and the treated samples were loaded into the wells. A voltage of $140 \mathrm{~V}$ and $80 \mathrm{~mA}$ was applied until the sample buffer bromophenol blue staining had reached the gel bottom.

After separation, 50\% methanol was used for gel fixation, which was then stained using silver stain according to Wray et al. (1981). Where the gel was picked and transferred into a small container and soaked in 50\% methanol /10\% acetic acid for at least 1 hour and methanol/acetic acid changed for 2-3 times. The gel was then rinsed with water, which must be changed at least 3 times. Solution A prepared from $0.8 \mathrm{~g}$ silver nitrate in $4 \mathrm{ml} \mathrm{DW}$. Solution B prepared from 21 $\mathrm{ml} 0.36 \% \mathrm{NaOH}$ with $1.4 \mathrm{ml}$ of 14.8 molarity (M) ammonium hydroxide; and solution $\mathrm{C}$ prepared by adding Solution A to solution B drop-wise with constant vigorous stirring so that allowed a brown precipitate to get clear; then water was added up to $100 \mathrm{ml}$ (solution $\mathrm{C}$ had to be used within 15 minutes). The gel was placed in a clean container and stained in Solution $\mathrm{C}$ for 15 minutes with constant gentle stirring. It was then rinsed twice in deionized water and soaked 2 minutes with gentle stirring. The gel was then removed into a clean container and washed in freshly prepared solution $\mathrm{D}(0.5 \mathrm{ml}$ of $1 \%$ citric acid mixed with $50 \mu \mathrm{l}$ of $38 \%$ formaldehyde, then water added up to $100 \mathrm{ml}$ ) so that the bands within 10 
minutes appeared. The staining was stopped by rinsing in $1 \%$ acetic acid. The gel was finally washed in water for at least 1 hour, at least 3 changes of water.

The gel was imaged and analyzed on the Molecular Imager Gel Doc ${ }^{\mathrm{TM}}$ XR System (Bio-Rad, USA). The relative Molecular Weights (MW) of separated proteins were calculated based on the MW standards of pre-stained protein ladder, which were electrophoresed on the same gel.

\section{RESULTS}

\section{SeM protein concentration}

The SeM protein concentration was detected both in the sediment and in the supernatants of the prepared extract. The sediment concentration of SeM protein was about $2.358 \mathrm{mg} / \mathrm{ml}$. While the supernatant concentration of the SeM protein was $0.364 \mathrm{mg} / \mathrm{ml}$.

\section{SDS-PAGE of extracted partially purified SeM protein}

Electrophoresis of the extracted sediment from SeM 1 in lane 1 revealed the appearance of a band at MW $70.9 \mathrm{kDa}$ (figures 1 and 2), While the electrophoresis of SeM 2 in lane 2 revealed the presence of 7 bands at MW of 105, 87.8, $70.9,61.1,44,37.9$ and $18.4 \mathrm{kDa}$ (figure 1 and figure 3). Five bands were detected in Lane 4 which represent SeM3 (figure 1 and figure 4) at MW 70.9, 58.9, 37.2, 29.8 and $18.3 \mathrm{kDa}$, and SeM 4 showed four bands in lane 5 at MW of 72.0, 58.6, 29.8 and $18.0 \mathrm{kDa}$ (figures 1 and 5).

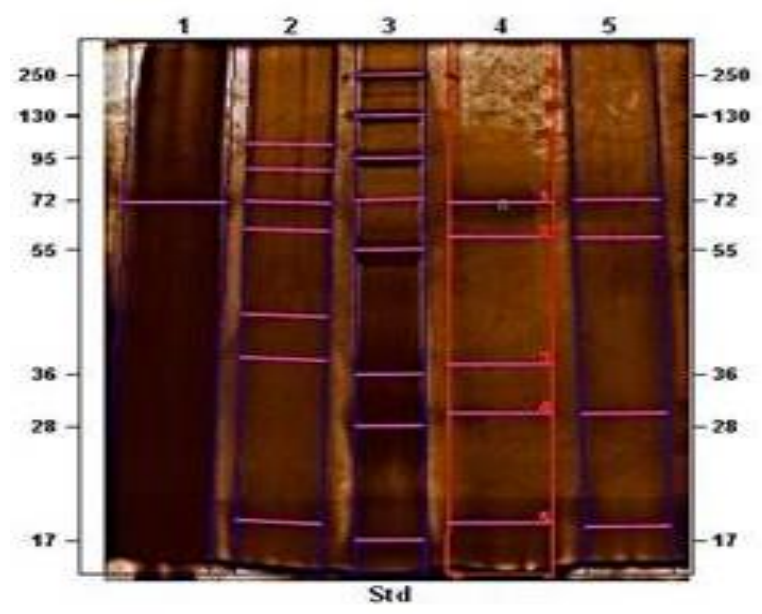

Figure 1. SDS-PAGE of four samples. Lane 1= SeM1; Lane 2=SeM 2; Lane 3= ladder; Lane 4= SeM 3 and Lane $5=\mathrm{SeM} 4$

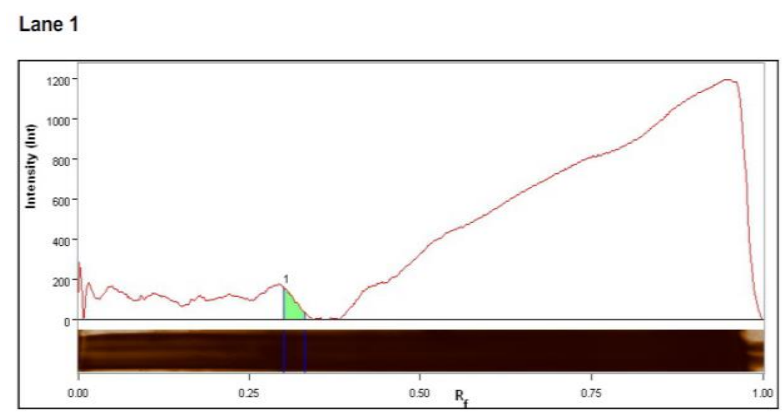

Figure 2. SDS-PAGE of SeM 1 showed one band

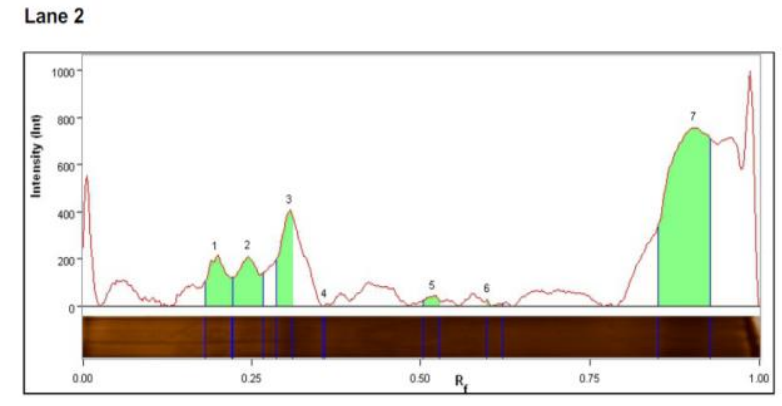

Figure 3. SDS-PAGE of SeM2 showed seven bands

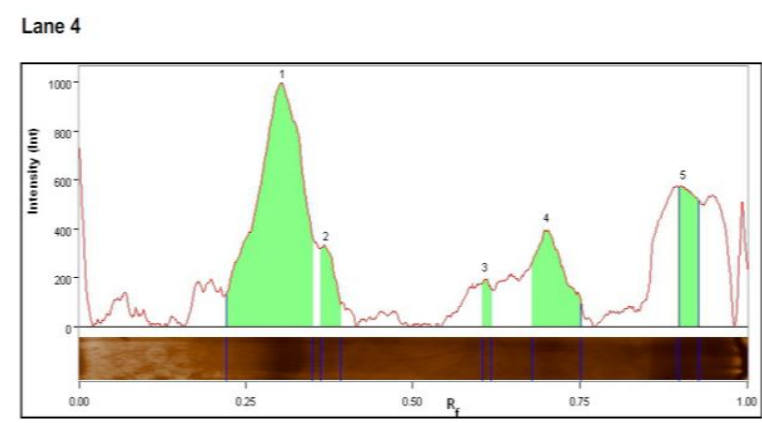

Figure 4. SDS-PAGE of SeM3 showed five bands

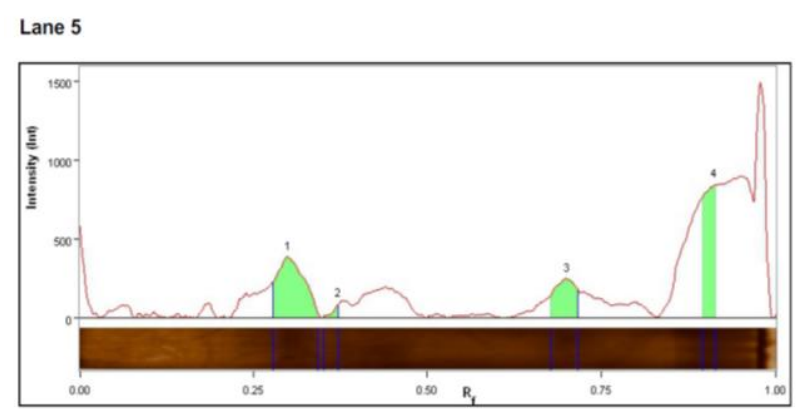

Figure 5. SDS-PAGE of SeM4 showed four bands 
Streptococcus equi subspecies equi causes strangles, a highly contagious disease of the nasopharynx and draining lymph nodes of members of the family Equidae. S. equi is a Streptococcus from Lancefield group C (Boyle et al., 2018).

$\mathrm{M}$ proteins were first described for the Lancefield group A streptococci, and subsequently have been found on groups C and G streptococci (Jacks-Weis et al., 1982; Bisno et al., 1996). Thirty-three percent of horses investigated by Delph et al. (2018) had SeM antibody titers greater or equal to 1:12800, eight weeks after infection with S. equi. Also, Boyle et al. (2017) reported that Timoney and others (Sweeney et al., 2005) have suggested that horses with high SeM-specific serum antibody titers $(\geq 3200)$ may be suitable equine vaccinated for $S$. equi with the attenuated-live intranasal S. equi vaccine.

In the present study, electrophoresis of the extracted sediment of SeM1 in lane 1 revealed the appearance of one band at MW $70.9 \mathrm{kDa}$ (figure1 and figure2), lane 2 revealed the presence of 7 bands at MW of 105, 87.8, 70.9, 61.1, 44, 37.9 and $18.4 \mathrm{kDa}$ (figure1 and figure3), lane 4 showed five bands at MW 70.9, 58.9, 37.2, 29.8 and 18.3 kDa (figure1 and figure 4), and lane 5 showed four bands at MW of 72.0, 58.6, 29.8 and 18.0 kDa (figure 1 and figure 5).

Frequent centrifugation of supernatants (SeM2, SeM3 and SeM4) revealed the presence of four proteins with a MW of 58.9, 37.2, 29.8 and $18.3 \mathrm{kDa}$, while SeM was a protein of 58-kDa M-like protein which was considered as major virulence factor and protective antigen with antiphagocytic properties (Timoney et al., 1997). Timoney and Trachman (1985) also found that M-like protein was analogous to group A streptococci M-protein molecules, which is structurally quite complex with functionally heterogeneous regions, including 29 and $37 \mathrm{kDa}$ fragments that carry determinants that induce serum bactericidal antibodies. No protein with a MW 41 and $46 \mathrm{kDa}$ was present in the present analysis, while Galan and Timoney (1985) found that 41 and $46 \mathrm{kDa}$ fragments were responsible for the stimulation of the mucosal immune response and the independence of the mucosal and systemic immune response to $S$. equi clearly proved in horses.

In the present study, a fractionation of protein with a $\mathrm{MW}$ of $18.3 \mathrm{kDa}$ was also obtained this result was reported by Groschup et al. (1990), who detected bands at 70, 54, 42, 40, 31-28,17-15 and less than 15kDa in S. equi by using SDSPAGE and Coomassie blue staining.

\section{CONCLUSION}

Streptococcus equi subspecies equi is an important equine pathogen. Further modification of SeM extraction revealed the presence of heterogeneous complex fragments of SeM. This multiple centrifugations modification procedure resulted in more purified antigen. There is a wide variety of SeM protein among $S$. equi isolates. The SDS profile analysis of SeM protein among $S$. equi isolates is recommended as a diagnostic test for strangles. Further studies are still required so that the modified preparation of SeM can be used for immunization.

\section{DECLARATIONS}

\section{Competing interests}

The authors declared that they have no competing interests.

\section{Consent to publish} elsewhere.

All the authors were aware of the fact and agreed to be so named. The data of this study did not partially published

\section{Author`s contributions}

Shaimaa M.E. Abdelmageed collected the data, participated in the design of the work protocol, performed the laboratory work, and was involved in the preparation of the manuscript. Soumaya S.A. El-Shafii found the research idea, shared in the performed data and designed the work protocol. J. El Jakee participated in the design of the work protocol, contributed to the manuscript review and interpreted the results. All authors were involved in the preparation of the manuscript and had read and approved the final manuscript.

\section{REFERENCES}

Bisno AL, Collins CM and Turner JC (1996). M proteins of group C streptococci isolated from patients with acute pharyngitis. Journal of clinical microbiology, 34(10): 2511-2515. DOI: https://jcm.asm.org/content/34/10/2511.

Boyle AG, Smith MA, Boston RC and Stefanovski D (2017). A case-control study developing a model for predicting risk factors for high SeM-specific antibody titers after natural outbreaks of Streptococcus equi subsp equi infection in horses. Journal of the American Veterinary Medical Association, 250(12): 1432-1439. DOI: https://doi.org/10.2460/javma.250.12.1432.

Boyle AG, Timoney JF, Newton JR, Hines MT, Waller AS and Buchanan B (2018). Streptococcus equi infections in horses: guidelines for treatment, control, and prevention of strangles-revised consensus statement. Journal of Veterinary Internal Medicine; 32(2): 633-647. DOI: https://doi.org/10.1111/jvim.15043. 
Delph KM, Beard LA, Trimble AC, Sutter ME, Timoney JF and Morrow JK (2018). Strangles, convalescent Streptococcus equi subspecies equi M antibody titers, and presence of complications. Journal of Veterinary Internal Medicine. 33(1): 275-279. DOI: https://doi.org/10.1111/jvim.15388.

Ferris RA, Palmer BA, Borlee BR and McCue PM (2017). Ability of chromogenic agar, MALDI-TOF, API $20 \mathrm{E}$ and 20 strep strips, and BBL crystal enteric and Gram-positive identification kits to precisely identify common equine uterine pathogens. Journal of equine veterinary science, 57: 35-40. DOI: https://doi.org/10.1016/j.jevs.2017.06.009

Galan JE and Timoney JF (1985). Mucosal nasopharyngeal immune responses of horses to protein antigens of Streptococcus equi. Infection and immunity, 47(3): 623-628. DOI: https://doi.org/10.1128/IAI.masthead.85-1.

Gallagher SR (2006). One-dimensional SDS gel electrophoresis of proteins. Current protocols in molecular biology, pp. 10-12. DOI: https://doi.org/10.1002/0471142735.im0804s75.

Groschup M, Müller HP, Weiss R and Schliesser T (1990). Studies of antigenic components in acid extracts of group C streptococci with special reference to Streptococcus equi.Zentralblatt für Bakteriologie, 273(4): 459-470. DOI: https://doi.org/10.1016/S0934-8840(11)80453-6.

Ikhuoso OA, Monroy JC, Rivas-Caceres RR, Cipriano-Salazar M and Pliego AB (2019). Streptococcus equi in equine: diagnostic and healthy performance impacts. Journal of Equine Veterinary Science, 85: 102870. DOI: https://doi.org/10.1016/j.jevs.2019.102870.

Jacks-Weis J, Kim YO and Cleary PP (1982). Restricted deposition of C3 on M4 group A streptococci: correlation with resistance to phagocytosis. The Journal of Immunology, 128(4): 1897-1902. Available at: https://www.jimmunol.org/content/128/4/1897.

Judd RC (2009). Peptide mapping by sodium dodecyl sulfate-polyacrylamide gel electrophoresis. In the protein protocols handbook, Humana Press, Totowa, NJ, pp. 963-968. DOI: https://doi.org/10.1385/1-59259-169-8:553.

Kalagiri R, Adam K and Hunter T (2020). Empirical evidence of cellular histidine phosphorylation by immunoblotting using pHis mAbs. In Histidine Phosphorylation, Humana, New York, NY, pp. 181-191. DOI: https://doi.org/10.1007/978-1-4939-98845_12.

Kasuya K, Tanaka N, Oshima F, Fujisawa N, Saito M, Tagami K, Niwa H and Sasai K (2019). Genetic analysis of Streptococcus equi subsp. equi isolated from horses imported into Japan. Journal of Veterinary Medical Science, 81(6): 924-927. DOI: https://doi.org/10.1292/jvms.18-0656.

Laemmli UK (1970). Cleavage of structural proteins during the assembly of the head of bacteriophage T4. Nature, 227(5259): 680. DOI: https://doi.org/10.1038/227680a0.

Lowry OH, Rosebrough NJ, Farr AL and Randall RJ (1951). Protein measurement with the Folin phenol reagent. Journal of biological chemistry, 193(1): 265-275. Available at: https://www.jbc.org/content/193/1/265.long.

Robinson C, Frykberg L, Flock M, Guss B, Waller AS and Flock J I (2018). Strangvac: A recombinant fusion protein vaccine that protects against strangles, caused by Streptococcus equi. Vaccine, 36(11): 1484-1490. DOI: https://doi.org/10.1016/j.vaccine.2018.01.030.

Staali L, Mörgelin M, Björck L and Tapper H (2003). Streptococcus pyogenes expressing M and M-like surface proteins are phagocytosed but survive inside human neutrophils. Cellular microbiology, 5(4): 253-265. DOI: https://doi.org/10.1046/j.14625822.2003.00272.x.

Sweeney CR, Timoney JF, Newton JR and Hines MT (2005). Streptococcus equi infections in horses: guidelines for treatment, control, and prevention of strangles. Journal of Veterinary Internal Medicine, 19(1): 123-134. DOI: https://doi.org/10.1111/j.1939-1676.2005.tb02671.x.

Tartor YH, Gharieb N, Ali W, EL-Naenaeey ES and Ammar A (2019). Rapid and precise diagnostic tests for S. equi: An etiologic agent of equine strangles. Zagazig Veterinary Journal, 47(2): 146-159. DOI: https://doi.org/10.21608/zvjz.2019.9896.1024

Taylor SD and Wilson WD (2006). Streptococcus equi subsp. equi (Strangles) Infection. Clinical Techniques in Equine Practice, 5(3): 211-217. DOI: https://doi.org/10.1053/j.ctep.2006.03.016.

Timoney JF and Trachman JU (1985). Immunologically reactive proteins of Streptococcus equi. Infection and immunity, 48(1): 29-34. DOI: https://doi.org/10.1128/IAI.48.1.29-34.1985.

Timoney JF, Artiushin SC and Boschwitz JS (1997). Comparison of the sequences and functions of Streptococcus equi M-like proteins SeM and SzPSe. Infection and immunity, 65(9): 3600-3605. DOI: https://doi.org/10.1128/IAI.65.9.3600-3605.1997.

Timoney JF, Suther P, Velineni S and Artiushin SC (2014). The antiphagocytic activity of SeM of Streptococcus equi requires capsule. Journal of equine science, 25(2): 53-56. DOI: https://doi.org/10.1294/jes.25.53.

Woolcock JB (1974). Purification and antigenicity of an M-like protein of Streptococcus equi. Infection and immunity, 10(1): 116122. DOI: https://doi.org/10.1128/IAI.10.1.116-122.1974.

Wray W, Boulikas T, Wray VP and Hancock R (1981). Silver staining of proteins in polyacrylamide gels. Analytical biochemistry, 118(1): 197-203. DOI: https://doi.org/10.1016/0003-2697(81)90179-2. 